\title{
Study to compare between paperless partogram and modified who partogram in management of labour
}

\author{
Veena L.*, Sarojini, Prathima Anagondanahalli, Prakash, Suchitra
}

Department of Obstetrics and Gynecology, Bangalore Medical College and Research Institute, Bangalore, Karnataka, India

Received: 16 November 2017

Accepted: 24 November 2017

*Correspondence:

Dr. Veena L.,

E-mail: veenhonappa@gmail.com

Copyright: () the author(s), publisher and licensee Medip Academy. This is an open-access article distributed under the terms of the Creative Commons Attribution Non-Commercial License, which permits unrestricted non-commercial use, distribution, and reproduction in any medium, provided the original work is properly cited.

\section{ABSTRACT}

Background: Partogram is being used since 1954 when Friedman described it for monitoring progress of labour. The Paperless Partogram proposed by Dr. Debdas is a low-skill method for detection of abnormal labour. The main aim of the study is to know efficacy and user friendliness of paperless partogram in comparison with WHO partogram in monitoring and management of labour.

Methods: It's a prospective observational study conducted at Vanivilas hospital where 200 women in labour were included. 6 resident doctors in shifts were asked to fill partograms 100 each for paperless (group A) and WHO (group B).

Results: Paperless partogram has scored better than WHO partogram in terms of documentation, learning, time for data entry, cost effectiveness and monitoring of labour.

Conclusions: In our study paperless partogram was found to be preferred for monitoring of labour.

Keywords: Labour, Paperless partogram, WHO partogram

\section{INTRODUCTION}

Maternal mortality is unacceptably high, about 830 women die from pregnancy or childbirth-related complications around the world every day. It was estimated that in 2015, roughly 303000 women died during and following pregnancy and childbirth. Between 2016 and 2030, as part of the Sustainable Development Goals, the target is to reduce the global maternal mortality ratio to less than 70 per 100000 live births. ${ }^{1}$

The partograph is a graphical representation of the various events of labour plotted against time. It serves to be a very cost effective and affordable health intervention for monitoring labour and appropriate decision making. The partograph was originally developed by Friedman in
1954 based on his observations on labours of women in Zimbabwe (then Rhodesia).

The earliest WHO partograph was the Composite partograph which was further modified in 2000 by eliminating the latent phase to yield the WHO modified partograph. As a part of the Safe Motherhood Initiative (launched in 1987) WHO recommends universal application of the Modified Partogram. Despite the positive reports of improved maternal outcomes resulting from correct partograph there is underuse and incorrect use of the partograph at all levels of maternity care. Several factors have been implicated to the cause of this low use such as lack of awareness and proper training, low availability of partographs, negative perceptions of the partograph, high patient load, inadequate staff at the 
facilities, lack of supervision, and negative attitudes among some of the health workers. ${ }^{2}$

Dr.Debdas argues that the WHO partogram fails to meet the organization's own requirements for appropriate technology. Debdas has proposed the Paperless Partogram designed for use by clinicians/ midwives in low resource areas. It uses a simple, non-time consuming, two step calculation requiring only basic addition and the reading of a clock/ watch. It identifies slow progress of labour, the time to intervene and terminate labour or to transfer a woman to higher centers with facilities for Caesarean section. ${ }^{3}$

The present study is used to evaluate user friendliness of paperless partogram in comparison with WHO partogram in monitoring and management of labour.

\section{METHODS}

The present study was carried out in the Vanivilas Hospital attached to Department of Obstetrics and Gynecology, BMCRI Bangalore India in January and February 2017.

It was a hospital based prospective analytical study. During the period of our study we studied the course of labour in 200 women with singleton, term (37-41 weeks) pregnancies with vertex presentation in spontaneous labour without any complications attending the labour room for delivery. Demographic details and history of all patients were taken and those willing to participate after an informed and written consent were included in the study.

Half of the patients (100) were monitored by paperless partogram in group A and the other half were monitored by WHO modified partogram. The plotting of the WHO partographs was started as soon the cervical dilatation was $4 \mathrm{~cm}$ along with regular painful uterine contractions. In the paperless partogram calculation was two times, an ALERT ETD (estimated time of delivery) and an ACTION ETD. The outcome of labour was recorded at the end of each partograph.

There were 6 resident doctors working on shift duties in the labour room. They were trained about the use of either partographs (WHO modified and Paperless partograph) with which they monitored labour. Purposive sampling was done. A structured Questionnaire divided into 3 sections was used in the study.

Section 1- Questions designed to identify factors behind noncompliance of partographs.

Section 2- Preferences regarding use of partographs (WHO Modified or Paperless)

Section 3- User-friendliness, Teachability and over all Usefulness score of either partographs.
In order to produce a more objective assessment, scoring method was devised to elicit the user-friendliness. A score of 1-10 each for user-friendliness, teachability and overall usefulness was given to either partographs on the basis of observer's personal experience.

All partographs were checked for completeness. All the results were plotted in a master chart. Descriptive frequencies, percentage and charts were used and data analysis was done.

\section{RESULTS}

The following data was obtained from the present study.

During the study period 200 women in labour were monitored by the WHO and paperless partograph (100each). The baseline characteristics of the patients are as mentioned (Table 1).

Table 1: Baseline characteristics of the participants.

\begin{tabular}{|ll|l|}
\hline Variable & Range & $\begin{array}{l}\text { Both Group A } \\
\text { and Group B had } \\
\text { consistent results }\end{array}$ \\
\hline Age & $18-35 \mathrm{yrs}$ & $25 \pm 4.3$ \\
\hline $\begin{array}{l}\text { Nutritional } \\
\text { status (BMI) }\end{array}$ & $16-28 \mathrm{~kg} / \mathrm{m}^{2}$ & $23 \pm 3.6$ \\
\hline $\begin{array}{l}\text { Gestational } \\
\text { age }\end{array}$ & $36-42$ weeks & $38 \pm 2.4$ \\
\hline Temperature & $36-39$ & $36.9 \pm 0.2$ \\
\hline pulse & $60-90 \mathrm{beats} / \mathrm{min}$ & $72.5 \pm 4.4$ \\
\hline $\begin{array}{l}\text { BP } \\
\begin{array}{l}\text { Uterine } \\
\text { contractions } \\
\text { (/10minutes) }\end{array}\end{array}$ & $1-5$ & $108.5 \pm 9.5 / 75.9 \pm 9.2$ \\
\hline
\end{tabular}

In present study it was observed that most of the cases delivered before reaching the alert line/ETD i.e. $83 \%$ in case of Paperless partogram and $76 \%$ in case of WHO partograph.

Table 2: Distribution of cases in relation to alert and action line/ETD.

\begin{tabular}{|lllll|}
\hline & $\begin{array}{l}\text { Group A } \\
\text { (paperless } \\
\text { vartograph) }\end{array}$ & \multicolumn{2}{l|}{$\begin{array}{l}\text { Group B } \\
\text { (WHO }\end{array}$} \\
& $\begin{array}{l}\text { No. } \\
\text { partograph) }\end{array}$ & \% & No. & $\%$ \\
\hline $\begin{array}{l}\text { Within alert line/alert } \\
\text { ETD }\end{array}$ & 83 & 83 & 76 & 76 \\
\hline $\begin{array}{l}\text { Between alert line/alert } \\
\text { ETD and action } \\
\text { line/action ETD }\end{array}$ & 14 & 14 & 18 & 18 \\
\hline $\begin{array}{l}\text { Beyond action } \\
\text { line/ETD }\end{array}$ & 3 & 3 & 6 & 6 \\
\hline Total & 100 & 100 & 100 & 100 \\
\hline
\end{tabular}


$14 \%$ of cases monitored by Paperless partograph and $18 \%$ of cases monitored by WHO partograph delivered between the alert line/alert ETD and action line/action ETD. A minor proportion $3 \%$ in case of Paperless partograph and $6 \%$ in case of WHO partograph delivered beyond the action line/action ETD. These cases were properly reassessed and delivered so as to avoid complications of prolonged labour (Table 2).

Table 3: Mode of delivery.

\begin{tabular}{|lllll|}
\hline Variables & \multicolumn{2}{l}{$\begin{array}{l}\text { Group A } \\
\text { (paperless) }\end{array}$} & \multicolumn{2}{l|}{$\begin{array}{l}\text { Group B } \\
\text { (WHO) }\end{array}$} \\
& No. & $\mathbf{\%}$ & No. & \% \\
\hline Spontaneous vaginal & 85 & 85 & 79 & 79 \\
\hline Assisted vaginal & 2 & 2 & 3 & 3 \\
\hline Cesarean section & 13 & 13 & 18 & 18 \\
\hline
\end{tabular}

Further on following up for mode of delivery $85 \%$ of cases monitored by the Paperless partograph and $79 \%$ cases monitored by WHO partograph had a spontaneous delivery. Caesarean section was required in $13 \%$ cases monitored by Paperless partograph as against $18 \%$ cases of WHO partograph. 2 in Paperless group and 3 in WHO group required assisted delivery. Thus, course of labour with Paperless partograph was comparable with that of WHO modified partograph (Table 3).

Table 4: Assessment of factors of non-compliance of partographs.

\begin{tabular}{|c|c|c|c|c|c|}
\hline \multirow{2}{*}{\multicolumn{2}{|c|}{ Variables }} & \multicolumn{2}{|c|}{$\begin{array}{l}\text { Paperless } \\
\text { partogram }\end{array}$} & \multicolumn{2}{|c|}{$\begin{array}{l}\text { WHO } \\
\text { partogram }\end{array}$} \\
\hline & & No. & $\%$ & No. & $\%$ \\
\hline \multicolumn{2}{|c|}{$\begin{array}{l}\text { Difficulty in plotting and } \\
\text { maintaining partograph }\end{array}$} & 0 & 0 & 4 & 66.7 \\
\hline \multirow{4}{*}{$\begin{array}{l}\text { Factors of } \\
\text { noncompliance }\end{array}$} & Less staff & 0 & 0 & 1 & 16.6 \\
\hline & $\begin{array}{l}\text { Time } \\
\text { consuming }\end{array}$ & 0 & 0 & 1 & 16.6 \\
\hline & $\begin{array}{l}\text { High patient } \\
\text { load }\end{array}$ & 0 & 0 & 2 & 33.3 \\
\hline & $\begin{array}{l}\text { Complex } \\
\text { graph }\end{array}$ & 0 & 0 & 0 & 0 \\
\hline
\end{tabular}

Main message inferred from this table was that $66.7 \%$ of the residents expressed difficulty with the WHO Modified partograph while they found the Paperless partograph much easier to plot and monitor. The various factors for non-compliance of WHO Partograph was less staff $(16.6 \%)$, time consuming $(16.6 \%)$ and high patient load $(33.3 \%)$ (Table 4$)$.

On analysis of user friendliness, it was observed that the mean of user friendliness score was lower for WHO Modified $(3.65 \pm 0.45)$ than Paperless partograph $(8.1 \pm 0.9)$ which was highly significant. In regard to teachability also the paperless partograph was rated better than the WHO Modified partograph. Observers found it easier to train others (interns, nurses) on the utility and maintenance of Paperless partograph. As regards to the score for overall usefulness there was no significant difference because both partographs were equally effective in preventing prolonged labour and had almost similar rates of augmentation and operative intervention (Table 5).

Table 5: Score of user friendliness, teachability and overall usefulness.

\begin{tabular}{|c|c|c|}
\hline Variables & $\begin{array}{l}\text { Paperless } \\
\text { partogram }\end{array}$ & $\begin{array}{l}\text { WHO } \\
\text { partogram }\end{array}$ \\
\hline User friendliness & $8.1 \pm 0.9$ & $3.65 \pm 0.45$ \\
\hline Teachability & $7.9 \pm 0.6$ & $3.7 \pm 1.6$ \\
\hline Overall usefulness & $8.05 \pm 0.45$ & $7.5 \pm 0.5$ \\
\hline
\end{tabular}

On enquiring about their preference, 5 out of 6 resident doctors $(83.3 \%)$ preferred to use the paperless partograph rather than the WHO partograph (16.7\%) as it was simple, graphless and less time-consuming. In addition, also because of the ease of plotting and maintaining the Paperless partograph which required minimal time consumption (Table 6).

Table 6: Preference of residents for either partographs.

\begin{tabular}{|lll|}
\hline & Number & Percentage \\
\hline Paperless partogram & 5 & 83.3 \\
\hline WHO partogram & 1 & 16.7 \\
\hline
\end{tabular}

\section{DISCUSSION}

Labour monitoring and appropriate management is an important step to reduce maternal and perinatal morbidity and mortality.

Partogram is a bedside tool which depicts the progress of labour at a glance. It serves as an early warning system and assists in early decision making regarding augmentation, termination of labour and if necessary transfer to higher center for further management. It is an efficient means of exchange of technical information about the progress of labour between teams of care givers.

WHO recommends universal application of the Modified Partogram, but it is rarely used and when used is incorrectly interpreted.

The "Paperless Partogram" proposed by Dr.Debdas is simple and non-time consuming to monitor labour and aid in appropriate decision making.

In this context the present study was conducted at tertiary care center Department of Obstetrics and Gynecology, BMCRI Bangalore India to evaluate efficacy and user friendliness of paperless partogram in comparison with WHO partogram in monitoring and management of labour. 
In the present study we found that the course of labour with Paperless partograph was comparable with that of WHO modified partograph. Most of the cases (83\%) monitored by the Paperless had a normal course of labour and delivered before the alert ETD which was similar to those monitored by the WHO partograph (76\%). Only $14(14 \%)$ cases monitored by paperless partograph crossed the alert ETD and 3\% cases delivered beyond the action ETD. Similarly, 18(18\%) cases crossed the alert line in the WHO group and only $6(6 \%)$ cases delivered beyond the action line. Almost similar results were seen in a study conducted by Deblina et al in 2013 in Bankura Medical College, West Bengal where it was observed that $14.5 \%$ cases monitored by the paperless partograph delivered between alert and action ETD and only $1.8 \%$ beyond the action ETD. ${ }^{4}$

The main observation done in our study is that $66.7 \%$ residents faced difficulty in plotting and maintaining the WHO Modified partograph while none experienced difficulty with the Paperless partograph. The factors responsible for non-compliance of the WHO Modified partograph was less staff, more time consumption and high patient load. Major cause for poor use of WHO partogram is due to high patient load (33.3\%). Similar results were also seen in a study conducted by Rajashree Sharma at Assam where it was concluded that $66.7 \%$ of the residents expressed difficulty in plotting and maintaining the WHO partogram. ${ }^{5}$ Another study carried out by Margaret M Opiah in the Niger Delta Region of Nigeria in 2012 observed that non availability of partograph $(30.3 \%)$, shortage of staff $(19.4 \%)$, lack of knowledge and experience on the use of partographs by midwives were responsible for the low rates of partographic monitoring. ${ }^{6}$

Another important observation done in our study was that the mean user friendliness score was lower for the WHO Modified partograph $(3.65 \pm 0.45)$ while it was high for the paperless partograph $(8.1 \pm 0.9)$ which was significant. There was also significant difference of teachability score between the two groups i.e. average score for WHO

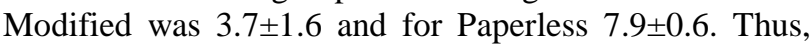
the Residents found it easier to teach the other staff like interns and nurses on paperless Partograph which improves reproducibility. Both partographs showed similar results in overall usefulness as they were equally effective in detecting abnormal labour. Similar observations were made in the study done by Deka $G$ et al in Assam the mean user friendliness score was high for the paperless partograph $(7.9 \pm 0.65)$. There was also significant difference of teachability score between the two groups with high score for the paperless partograph $(8.08 \pm 0.9)$. But there was no difference in overall usefulness score between the two groups. ${ }^{7}$

Even though there was no much difference in the monitoring and management of labour between the two preferred modes of partogram by all residents was paperless i.e.5 out of $6(83.3 \%)$ residents preferred paperless partogram. Similar results were observed in a study conducted by Fatouh E et al in Egypt in 2014 with the Paperless partograph where most of the nurses $(75 \%)$ preferred to use the paperless partograph over the traditional WHO partograph in the management of labour. ${ }^{8}$ In study conducted by Lingegowda $\mathrm{K}$ on comparison between WHO and paperless partograph in PESIMSR, Kuppam also concluded that the Paperless partograph was very simple to understand and can be implemented even in rural set up by midwives with minimal training. ${ }^{9}$

The Paperless partograph devised by Debdas was found to be as effective as the WHO Modified partograph in monitoring labour. Finally present study inferred that Paperless partograph is simple, safe, inexpensive, easy to learn, implement and highly effective means of monitoring labour and detecting abnormal labour, so it was more preferred by the resident staff.

\section{CONCLUSION}

In conclusion Paperless partograph has great prospects to prevent prolonged labour as it is simpler, less time consuming and graphless. It was easier to maintain and could be easily plotted even by those with minimal formal training on it as there was no graph to plot and no curve to chase. Also, it was found to be less complicated and required minimal time. Thus, it can serve to replace the WHO partograph particularly in areas with high workload of patients and shortage of manpower. It would be useful in rural India, the P.H.C. physician or a nurse can very easily know when to refer the case to a referral hospital before any maternal or fetal jeopardy occurs. We recommend further training on the use of the partogram to all health care providers in order to reduce maternal and neonatal mortality and to increase efficiency for better labour and delivery outcomes at the community level.

Funding: No funding sources

Conflict of interest: None declared

Ethical approval: The study was approved by the Institutional Ethics Committee

\section{REFERENCES}

1. World Health Organization. Maternal mortality. Available

at: http://www.who.int/mediacentre/factsheets/fs348/en/

2. Ogwan S, Karyabakabo Z, Rutebemberwa E. Assessment of partogram use during labour in Rujumbura Health Sub District, Rukungiri District, Uganda. Afr Health Sci. 2009;9(Supplement 1):S2734.

3. Debdas AK. Paperless Partogram. 41 ${ }^{\text {st }}$ Annual Scientific Session. SLJOG: 2008;30(1):124.

4. Roy D, Dey R. ETD- expected time of delivery- a new simple clinical tool for management of labour AICOG Patna. 2014:2. 
5. Sharma R. The Paperless partograph - The new userfriendly and simpler tool for monitoring labour. IOSR-JDMS. 2015;14(11):39-43.

6. Opiah MM, Ofi AB, Essien EJ, Monjok E. Knowledge and utilization of the partograph among midwives in the Niger Delta Region of Nigeria. Afr J Reprod Health. 2012 Mar 1;16(1):125-32.

7. Deka $G$ et al. The paperless partograph: can it be effective to replace the WHO modified partograph. Int J Reprod Contracept Obstet Gynecol. 2016 Feb; 5(2):452-5.

8. Fatouh E, Ramadan S. Effect of using paperless partogram on the management and outcome of labour and the nurses' opinion. J Edu Pract. 2015;6(8):17-23.

9. Lingegowda K, Bhuvaneswari, Shailaja N, Kulkarni $\mathrm{N}$, Bhatt SB, Vimala. Comparison of WHO partograph with Paperless partograph in the management of labour and to determine which is more user friendly. AICOG Patna. 2014:106-7.

Cite this article as: Veena L, Sarojini,

Anagondanahalli P, Prakash, Suchitra. Study to compare between paperless partogram and modified who partogram in management of labour. Int $\mathbf{J}$ Reprod Contracept Obstet Gynecol 2018;7:99-103. 